\title{
When mentoring matters: a French mentoring program for women in science
}

\author{
An innovative program addresses the need for support, encouragement and guidance on the part of women \\ scientists in the early years of their career, during their PhD.
}

\begin{abstract}
n the European Union in 2017, 44.4\% of the knowledge-intensive workforce was female. However, in many countries women are severely under-represented in scientific research; for example, they accounted for $33 \%$ in the European Union and $28 \%$ in France $^{1-3}$. Of researchers employed by European companies, $20 \%$ are women, a trend followed by France $^{1-3}$ (Fig. 1).

At French universities, the proportion of female students studying science varies according to discipline, with a clear preference for life and biomedical sciences
\end{abstract} (62\% of female science students) over fundamental and applied sciences including mathematics, physics, chemistry and computer sciences $(26 \%$ of female science students $)^{4}$. While young women are not afraid to engage in scientific studies early on, they often face several obstacles in a very masculine environment, including a general lack of support, ever-present and pervasive gender bias, and various forms of harassment, which lead them to develop a lack of self-confidence with respect to their professional abilities and to question their professional future. Over the past decades, many women have thus left their field to pursue personal rather than professional objectives after their $\mathrm{PhD}$. In our so-called evolved society in which balancing professional and personal life appears to be critical for self-fulfillment, neither men nor women should have to choose between these goals. A general lack of support to encourage young women to progress and value their scientific expertise and skills, together with a relatively low proportion of female role models in science, is largely responsible for the drop in their incentive to pursue a scientific career beyond the $\mathrm{PhD}$.

To address the need for support and guidance of female scientists in the early years of their career, a wide variety of mentoring programs have been developed in academic settings throughout Europe and the United States ${ }^{5-7}$. Although their format varies considerably, all share the common incentive of providing support, guidance and personalized advice and of helping mentees

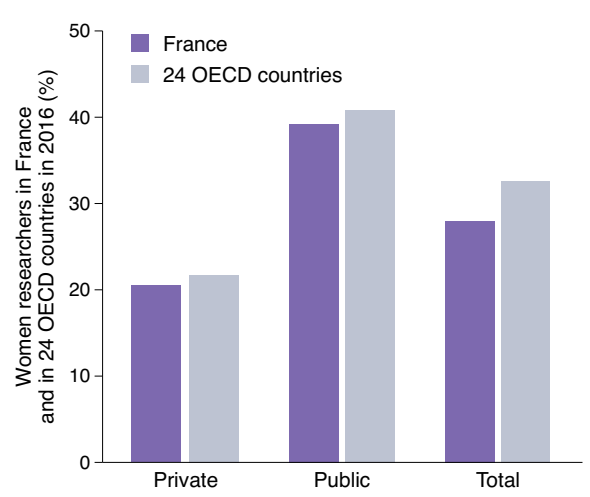

Fig. 1 | Proportion of female researchers in France and in 24 Organization for Economic Co-operation and Development (OECD) countries.

reflect on their career path choices with the aid of experienced mentors and training workshops. However, with no mentoring programs specifically directed toward female $\mathrm{PhD}$ students available at French universities until 2014, Femmes \& Sciences (https:// www.femmesetsciences.fr/), an association founded in 2000 that promotes science and technology and supports women throughout their scientific careers, pioneered a program that provides a nurturing environment for PhD students to discuss issues, seek guidance to plan their career paths and learn how to value their skills with a network of experienced scientific mentors. The program was launched at the University of Montpellier in 2015 with the support of the doctoral college ${ }^{8}$. Similar programs were established at the University of Toulouse in 2017 and at Paris-Saclay University in 2019, and more recently at the University of Nice, with further expansion in Strasbourg, Lyon, Grenoble, Bordeaux and other Parisian universities expected in the near future. Coordinated and driven by Femmes \& Sciences member volunteers, this innovative program bridges research laboratories and doctoral schools, who fully recognize and support the program. The main objective is to support, guide and train young female scientists at an important stage of their careers by providing them with an opportunity to benefit from unique and tailored advice from experienced scientists, to meet and learn from role models and to participate in group discussions and training sessions.

\section{Setting the stage: content and structure}

The mentoring program consists of three complementary schemes: regular one-on-one mentor-mentee meetings, group meetings to discuss issues concerning women in science or to attend presentations by established female scientists (testimonies), and career development workshops (Fig. 2a). The sequence of mentoring circles, testimonies and career development workshops is deliberately alternated over a 12-month period (Fig. 2b). Mentees can select as many group meetings as they wish to attend from the panel of mentoring circles, testimonies and workshops proposed by the program coordinators throughout the year.

Mentor-mentee pairs meet regularly (ideally once a month) to talk about the $\mathrm{PhD}$ itself and the mentee's career goals, to discuss specific issues related to the thesis and any obstacles beyond, and to address any doubts or concerns raised by the mentee. The mentor listens, guides and provides personalized advice to help the mentee think about her career choices and perspectives. Each mentor-mentee pair is unique, as the specific needs of a mentee may vary, and the mentor will tailor advice based on her or his own professional and personal experience.

Mentoring circles are group meetings led by one or several mentors, during which both mentees and mentors discuss specific topics determined at the beginning of the year. Some of the most popular mentoring circle themes concern work/life balance, careers in academia versus the private sector, careers in France or abroad, and self-confidence. Mentoring circles are generally held during lunch or a light dinner to encourage an informal atmosphere. 


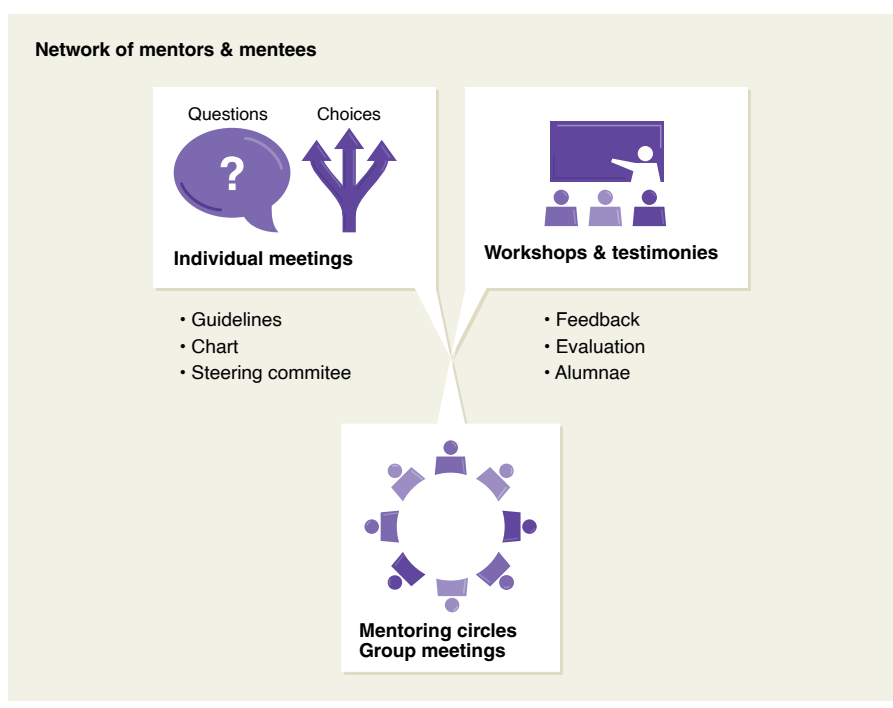

b

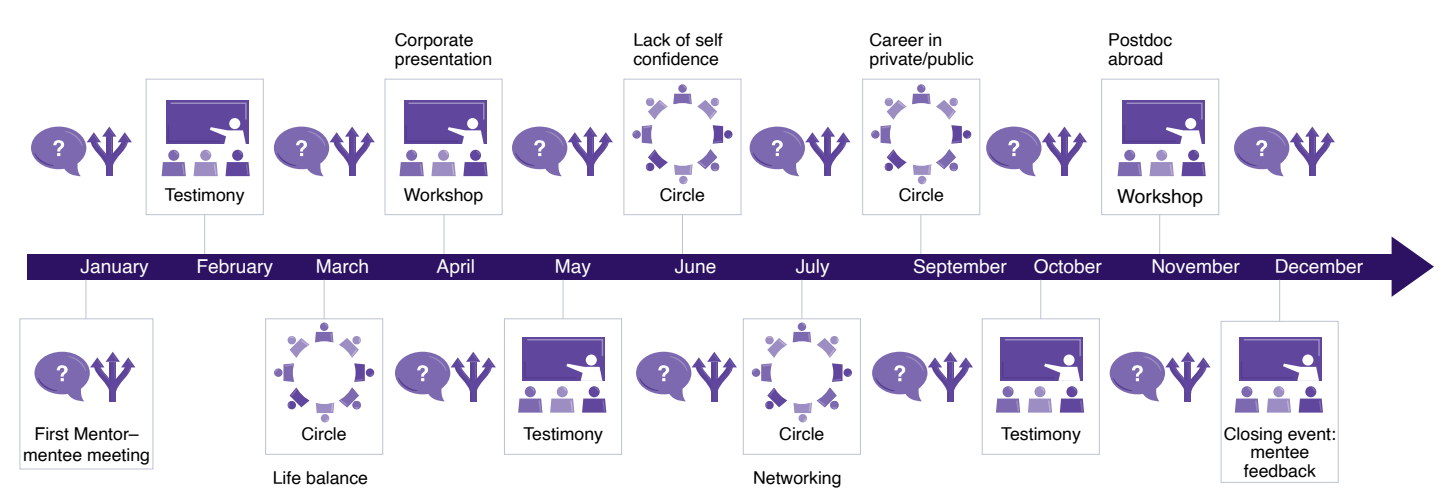

Fig. 2 | Structure and content of the mentoring program. $\mathbf{a}$, Three-faceted content of the mentoring program. $\mathbf{b}$, Sequence of events and different meetings proposed throughout the year (Montpellier, 2019).

Testimonies are presentations describing the career paths of established female scientists whose career choices and strategies within and beyond academia may inspire mentees. For example, an editorial writer, a company CEO and a scientific culture communication expert were invited to describe their daily job and career paths after their $\mathrm{PhD}$ in the mentoring program in Montpellier.

Career development workshops provide coaching and training for essential career development steps; for example, corporate presentation, preparing a postdoc abroad and professional networking.

A steering committee consisting of members of Femmes \& Sciences affiliated with universities, public research institutions or the private sector oversees the program's progress, deciding on the content and coordination of the mentoring circles and workshops, assessing new needs, addressing problems and evaluating the program annually. Upon engaging in the program, both mentors and mentees must agree to the mentoring charter, which contains basic rules to ensure reciprocal respect as well as mutual consent to engage in regular meetings and commit to the 12-month duration of the program. Mentors do not substitute for the $\mathrm{PhD}$ supervisor in any way, but engage in a positive and constructive relationship to support and guide the mentees throughout their PhD and beyond in their search for a postdoctoral position in academia or a job at a private company.

\section{Program participants}

Mentors are experienced scientists, female or male, who hold a PhD and may work in academia or industry. They are integrated in the program after training that provides them with basic guidelines and recommendations as to their role and limits ${ }^{9-11}$. Their role consists of active listening, guiding and encouraging the mentee: explaining how the system functions according to formal rules and know-how based on her or his own professional and personal experience. While a $\mathrm{PhD}$ supervisor teaches her or his student specific techniques and skills in well-defined scientific field, the mentor will accompany and nurture the mentee, passing on several less well-defined keys to success based on her or his scientific background, career path and experience. Mentors may also introduce a mentee into scientific networks and explain the importance of establishing professional networks and recommend strategies that will be important for the mentee's career path and professional development. As volunteers, mentors do not receive any compensation for their participation in the program.

The number of mentors and consequently of mentor-mentee pairs in the Montpellier mentoring program increased from 15 in 2015 to 50 in 2018 and ever since through 2021. In Toulouse the number of mentor-mentee pairs has deliberately been maintained under 10 . 
a

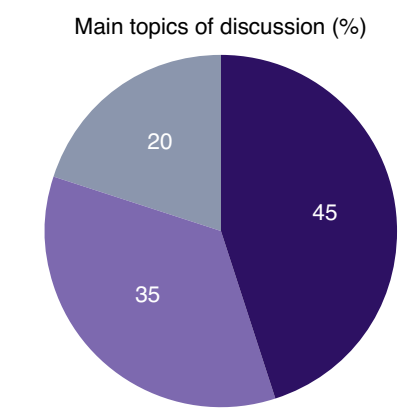

$\mathrm{PhD}$

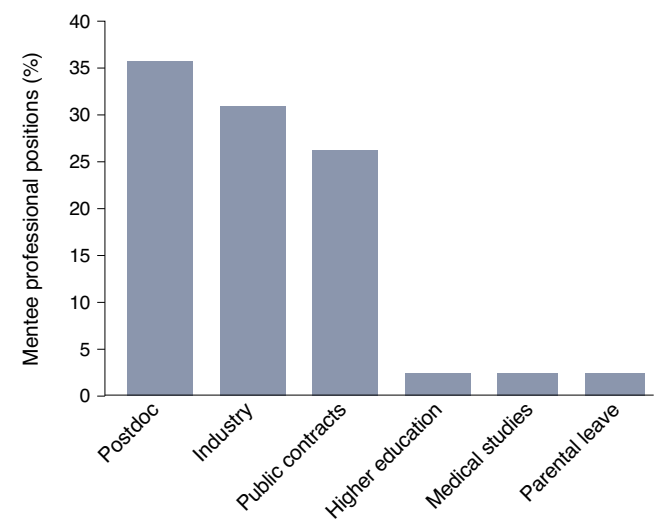

b

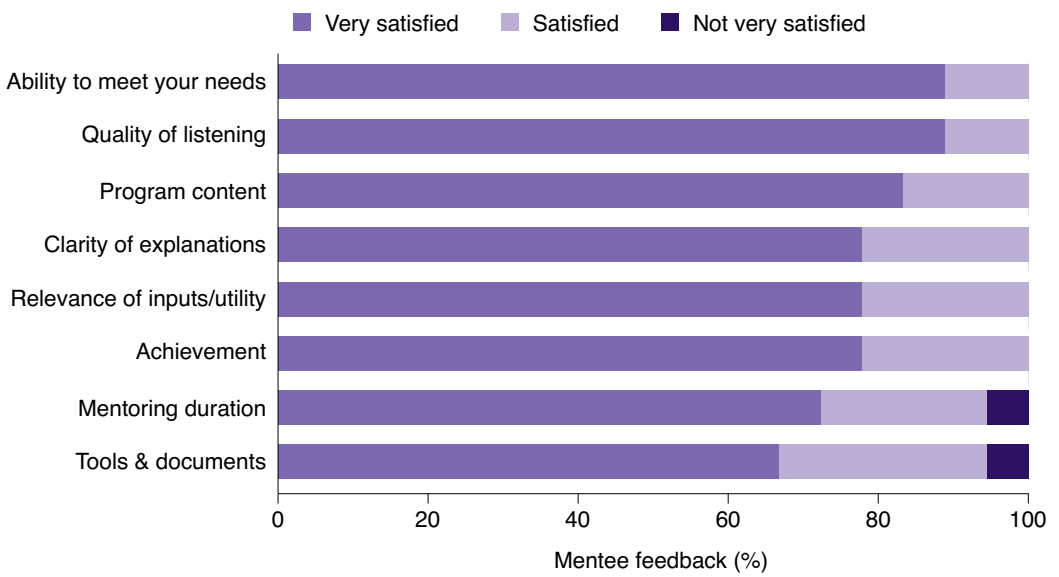

Fig. 3 | Evaluation and follow-up of the mentoring program. a, Main topics of discussion between mentors and mentees during one-on-one meetings as based on follow up sheets from Montpellier in 2019. b. Evaluation of different aspects of the mentoring program by mentees of Montpellier Mentoring Program 2019. c, Career positions after their PhD defense of the mentees who attended the Montpellier mentoring program between 2015 and 2019.

In Paris-Saclay the program was launched with 9 mentors in 2018 and increased to 43 and 44 in 2019 and 2020, respectively. Most mentors were affiliated to CNRS, France's national scientific research institution; followed by INSERM, the French national institution for health and medical research; and INRAE, the national research institution on agriculture, food and environment, and universities.

Mentees commit to meet their mentor on a regular basis and to attend collective activities. A minimum of 20 hours is required for validation by the university's doctoral college. Over the past two years, $\mathrm{PhD}$ students from a variety of scientific disciplines enrolled in the mentoring programs, including students from chemistry, physics, mathematics, economics and political science, biology (biochemistry, life and health sciences), environmental science-ecology and agronomy. The program was most popular with $\mathrm{PhD}$ students in their first and second year, but students in their third and fourth year as well as several postdocs also attended.

\section{Mentor-mentee matching and estab- lishment of a trusting relationship} The spirit of the program is based on the assumption that open discussions and transfer of experience are facilitated by a caring and trustworthy climate. To favor freedom of speech, preserve the confidentiality of discussions and limit conflicts of interest, matched mentors and mentees should belong to different research institutes. Moreover, to prompt mentormentee pairing based on human affinity, the program organizes 'speed-meeting' sessions during which each mentee gets to meet different mentors. Mentors briefly describe their career path, personal and professional experience, and motivation to participate in the program. Mentees describe their career aims and interests that have led them to enroll in the program, such as seeking advice from female scientists, integrating into a female professional network, gaining self-confidence and finding support when encountering difficulties that cannot be addressed alone. The mentees then select their top three mentor choices. It is not uncommon for mentees to choose a mentor from the same cultural background. Some mentees choose mentors from the private sector so they can gain insight into an unfamiliar world. Some mentees prefer to be mentored by men, as they believe men's career planning strategies differ from those of women and wish to learn from such perspectives. Some mentees feel more comfortable with mentors from the same field of expertise as theirs. However, many mentees choose mentors with a different scientific background from their own. Mentors are matched to mentees by the steering board in order to accommodate all requests as well as possible, and all participants are required to sign the mentoring charter.

Although mentor-mentee pairs are initiated on the basis of affinity, a trusting relationship will build up over time and through regular meetings that take place in a confidential and constructive climate. During the first couple of meetings, mentor and mentee have to get to know each other and define issues, needs and objectives. The mentor should make the mentee feel comfortable enough to start confiding and will then be able to help her reflect on appropriate choices and perspectives to balance personal life with professional development. Meetings are usually face to face, although in cases of lengthy travel by either the mentor or the mentee or confinement due to COVID-19, video conference meetings can also be scheduled.

Feedback and follow-up during and beyond the program. Mentor and mentee pairs are asked to complete a follow-up sheet for each meeting indicating the date, duration and a brief description of the content of the discussion. The contents of these monthly meetings are analyzed anonymously to assess the overall content of discussions, reflecting issues that mentees need to discuss with their mentors (Fig. 3a). At the end of the program, mentees and mentors fill out an evaluation survey in which they are asked to mark the utility and quality of the different training sessions, mentoring circles and presentations by female scientists. They are also asked to make suggestions to enable the steering committee to adjust and improve the program (Fig. 3b).

The 12-month program concludes with a testimonials evening, during which mentors and mentees are invited to describe and 
share their experience with other mentors and mentees from the same program and with the next generation of mentors and mentees-to-be who wish to enroll. Keywords that the mentees associate with the mentoring program convey positive and constructive feelings indicative of the nurturing and trusting yet stimulating environment the mentors succeed in establishing, as well as notions associated with fulfillment, opportunity, solidarity, networking and professionalism. Mentees are also asked if they wish to join the network of alumnae-now a professional network of scientific contacts but also a source of future mentors once they have made progress in their careers. Mentees are contacted every year to follow up on their professional status and career paths. Since 2015, following their $\mathrm{PhD}$, the majority of mentees from the Montpellier program have secured positions in academia or in the private sector after their $\mathrm{PhD}$, indicating the program's positive influence (Fig. 3c).

\section{COVID-associated adaptation}

COVID-associated measures such as lockdowns and social distancing brought many restrictions to the original program, which relies strongly on human contact and discussion. Faced with these restrictions, we chose to adapt the program by avoiding physical group meetings and workshops and moving them online. The nature and frequency of mentor-mentee meetings also varied, with time, work and personal constraints causing some mentors to become less available or mentees having greater need of support. At the turn of 2020, training sessions for new mentors and mentees-to-be have so far been scheduled through virtual platforms.

\section{Outcome and perspectives}

The mentoring program established by Femmes \& Sciences was designed to meet a specific need for guidance of female PhD students during their career path development, to help them gain confidence and nurture their ability to value their skills. The spirit of this program is intended as caring and constructive, as well as dynamic and stimulating, in a trusting and professional environment. Beyond the content of the program itself, three levels of networking were observed: first, between mentors and mentees; second, among mentees from different scientific fields, who developed personal and professional solidarity throughout the group meetings and training sessions they attended; and third, between mentors, who developed new interactions through common objectives with colleagues from different research institutes and organizations. Moreover, beyond the qualitative training aspects, the program prompted greater open-mindedness in most mentees by broadening their career perspectives and providing them with tools and strategies to achieve their professional goals. The participation of male mentors in the program, although they made up less than $10 \%$ of all mentors, constituted an important contribution, as they provided a different perspective that was considered with interest by several mentees, as well as a strong intention to support women in their scientific career. Last but not least, many mentor-mentee pairs developed a relationship persisting well after the end of the program, contributing to establish intergenerational networks between women in science.

Once the pioneering program was established in Montpellier, Femmes \& Sciences organized its annual meeting on this theme. The 2017 Femmes \& Sciences Meeting ${ }^{7}$ was a culmination that earned the program formal recognition and support by French institutions, including Montpellier University, CNRS, INSERM, INRAE and IRD. The short-term outcome is the successful professional entry of young women with $\mathrm{PhDs}$ who develop a more assertive approach to building their career paths. In the longer term, the program will increase the proportion of female scientists with PhDs in academic positions, as well as in the private sector. As such, the success of the program at the Universities of Montpellier, Toulouse and Paris-Saclay has prompted the Ministry of Higher Education, Research and Innovation to ask Femmes \& Sciences help bring the program to several other French universities.

\section{Julie Batut (D), Marina Kvaskoff ${ }^{2}$ and May C. Morris (D) ${ }^{3 凶}$}

${ }^{1}$ Unité de Biologie Moleculaire, Cellulaire et du Développement (MCD, UMR5077), Centre de Biologie Intégrative (CBI, FR 3743), Université de Toulouse, CNRS, UPS, Toulouse, France. ${ }^{2}$ Paris-Saclay University, UVSQ, Univ. Paris-Sud, Inserm, Gustave Roussy, "Exposome and Heredity" team, CESP, F-94805, Villejuif, France. ${ }^{3}$ Institut des Biomolécules Max Mousseron, CNRS-UMR 5247, University of Montpellier, Montpellier, France.

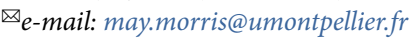

Published online: 10 June 2021

https://doi.org/10.1038/s41587-021-00951-2

\section{References}

1. French Ministry of Higher Education, Research and Innovation. Key numbers for gender equality (2019). http://www.enseignementsup-recherche.gouv.fr/cid139695/esrichiffres-cles-de-l-egalite-femmes-hommes-parution-2019.html (2019).

2. French Ministry of Higher Education, Research and Innovation. Key numbers for gender equality (2020) https://www.enseignementsup-recherche.gouv.fr/cid150061/esrichiffres-cles-de-l-egalite-femmes-hommes-parution-2020.html (2020).

3. She Figures 2018. https://ec.europa.eu/info/publications/shefigures-2018_en (2019).

4. French Ministry of Education. Youth and sports: girls and boys on the path to equality from school to higher education (edition 2020). https://www.education.gouv.fr/filles-etgarcons-sur-le-chemin-de-l-egalite-de-l-ecolel-enseignement-superieur-edition-2020-289508 (2020).

5. Fridkis-Hareli, M. Nat. Biotechnol. 29, 287-288 (2011).

6. Kuhn, C. \& Castaño, Z. Nat. Biotechnol. 34, 781-783 (2016).

7. Eument-net. Establishing Mentoring in Europe (2008); https:// www.eument-net.eu/eument-net-guideline-manual/

8. Proceedings Annual Meeting Femmes \& Sciences 2017 (2017); https://328f4cc6-2065-478e-9e6f-b3e67f24b6bc.filesusr.com/ ugd/5836fc_c7aa860334c94fofaa52528548669f21.pdf

9. Lee, A., Dennis, C. \& Campbell, P. Nature 447, 791-797 (2007).

10. Handelsman, J., Pfund, C., Lauffer, S.M. \& Pribbenow, C.M. Entering mentoring (2005); https://www.hhmi.org/sites/default/ files/Educational\%20Materials/Lab\%20Management/entering mentoring.pdf

11. Höppel, Dagmar (ed.). Recommendations for Successful Mentoring Relationships (LaKoG, 2014).

\section{Acknowledgements}

May C. Morris, Julie Batut and Marina Kvaskoff are members of the French association "Femmes \& Sciences" (Women \& Science) and the pioneering coordinators of the mentoring program in Montpellier, Toulouse and Paris-Saclay, respectively. We thank Claudine Hermann and Evelyne Nakache, with whom the mentoring program project was initially discussed, for their kind advice and support and for critical reading of the manuscript. We thank Florence Apparailly, Julie Bayle, Elsa Compte, Martine Lumbreras, Danièle Noel and Pascale Perrin, members of the steering board who helped establish the first mentoring program in Montpellier. We are also grateful to the president of Montpellier University, Philippe Augé, the vice-president Agnès Fichard-Carroll and the director of the Doctoral College Marc Bouvy for support and funding since 2017. We thank Dominique Morello, Martine Knibiehler, Marta Kwapisz, Didier Trouche and the CBI PhD program committee, who helped establish and coordinate the mentoring program in Toulouse. We are also grateful to Catherine Armengaud, gender equality officer at the Toulouse Paul Sabatier University; Muriel Mercier-Bonin and $\square \quad$ Claude Maranges, SEVAB; and Florence Larminat and Philippe Valet, BSB, Toulouse doctoral schools, for their continuous support. We acknowledge the DRDFE Occitanie (Regional Delegation for Women's Rights and Equality) for supporting the intraregional collaborative efforts to develop the program between Montpellier and Toulouse. We thank Sylvaine Turck-Chièze, Géraldine Liot, Julie Ménétrey, Gwenaëlle André-Leroux, Lucia Levato and Marie Destandau, who helped establish and coordinate the mentoring program in Paris-Saclay. We are also grateful to the Doctoral College of Paris-Saclay for its full support and funding, particularly Sylvie Pommier, Director of the Doctoral College; Sarah Boratav, Equality Officer at Paris-Saclay University; and Hamida Muller, administrative director of the Doctoral College, for their valued help. We thank Nadine Halberstadt, current president of Femmes \& Sciences, and all members of the Femmes \& Sciences association for their invaluable and continuous support. Finally, we would like to thank all the mentors, mentees, speakers and contributors who have participated in the various programs and helped bring them to life.

Competing interests

The authors declare no competing interests. 